\title{
Immobilization of D-allulose 3-Epimerase Into Magnetic Metal-Organic Framework Nanoparticles For Efficient Biocatalysis
}

\author{
Chun-Li Liu \\ Jiangnan University \\ Yankun Yang \\ Jiangnan University \\ Xiuxia Liu \\ Jiangnan University \\ Jinling Zhan \\ Jiangnan University \\ Zhonghu Bai \\ Jiangnan University
}

Kai Xue ( $D$ 429029579@qq.com )

Jiangnan University https://orcid.org/0000-0003-4210-6965

\section{Research Article}

Keywords: D-allulose, D-allulose 3-epimerase, D-fructose, immobilization, magnetic metal-organic frameworks

Posted Date: December 14th, 2021

DOI: https://doi.org/10.21203/rs.3.rs-1140187/v1

License: (c) (1) This work is licensed under a Creative Commons Attribution 4.0 International License. Read Full License 


\section{Abstract}

D-allulose is a rare low-calorie sugar that has many fundamental biological functions. D-allulose 3epimerase from Agrobacterium tumefaciens (AT-DAEase) catalyzes the conversion of D-fructose to Dallulose. The enzyme has attracted considerable attention because of its mild catalytic properties. However, the bioconversion efficiency and reusability of AT-DAEase limit its industrial application. Magnetic metal-organic frameworks (MOFs) have uniform pore sizes and large surface areas and can facilitate mass transport and enhance the capacity for enzyme immobilization. Here, we successfully encapsulated cobalt-type AT-DAEase into the cobalt-based magnetic MOF ZIF-67@Fe $\mathrm{O}_{4}$ using a selfassembly strategy. The AT-DAEase@ZIF-67@ $\mathrm{Fe}_{3} \mathrm{O}_{4}$ nanoparticles had higher catalytic activity $(65.1 \mathrm{U}$ mg

${ }^{1}$ ) and bioconversion ratio (38.1\%) than the free AT-DAEase. The optimal conditions for maximum enzyme activity of the AT-DAEase@ZIF-67@ $\mathrm{Fe}_{3} \mathrm{O}_{4}$ nanoparticles were $55^{\circ} \mathrm{C}$ and pH 8.0, which were significantly higher than those of the free AT-DAEase $\left(50^{\circ} \mathrm{C}\right.$ and pH 7.5). The AT-DAEase@ZIF-67@Fe $\mathrm{O}_{4}$ nanoparticles displayed significantly improved thermal stability and excellent recycling performance, with $80 \%$ retention of enzyme activity at temperature range of $45-70^{\circ} \mathrm{C}$ and $>45 \%$ of its initial activity after eight cycles of enzyme use. The AT-DAEase@ZIF-67@Fe $\mathrm{F}_{3} \mathrm{O}_{4}$ nanoparticles have great potential for largescale industrial preparation of D-allulose by immobilizing cobalt-type AT-DAEase into magnetic MOF ZIF$67 @ \mathrm{Fe}_{3} \mathrm{O}_{4}$.

\section{Introduction}

D-allulose is a C-3 epimer of D-fructose. This rare sugar has attracted much attention because of its many fundamental biological functions (Tseng et al. 2014). It has approximately $70 \%$ of the sweetness of sucrose but produces few calories because it inhibits hepatic lipogenic enzymes (Matsuo et al. 2002). Foods containing D-allulose show higher antioxidant activities than those without D-allulose (Sun et al. 2008). D-allulose has been 'generally recognized as safe' by the Food and Drug Administration (Zhang et al. 2013). Owing to these advantages over other sugars, D-allulose has been widely applied in food additives, medicine, cosmetics, flavors, and other preparations (Tseng et al. 2014). D-allulose has become an ideal substitute for sucrose, especially for obese patients or people seeking diet-related weight loss. However, D-allulose is rarely encountered in nature, and its' chemical synthesis is cumbersome, costly, and time-consuming (Patel et al. 2018). With the sustainable development of green chemistry and biotechnologies, enzymatic catalysis may prove valuable for the production of D-allulose because biocatalysts naturally evolve and have high selectivity (Sheldon and Woodley 2018).

Biological processes, such as enzymatic catalysis using ketose epimerase and aldose isomerase or other microbial reactions, are feasible for the synthesis of D-allulose (Kim et al. 2006; Zdarta et al. 2018). In recent years, the bio-production of D-allulose from the naturally available sugar D-fructose using Dallulose 3-epimerase (DAEase) has proven to be a potential method (Itoh et al. 2014; Zhang et al. 2013). DAEase for C-3 epimerization of D-fructose to D-allulose was identified and characterized from Agrobacterium tumefaciens (A. tumefaciens) (Kim et al. 2006), Clostridium cellulolyticum (C. 
cellulolyticum) H10 (Mu et al. 2011), Ruminococcus sp. (Zhu et al. 2012), and Bacillus sp. (Patel et al. 2021), and metagenomics (Patel et al. 2020). DAEase from A. tumefaciens (AT-DAEase) is more thermally stable than other DAEases and is potentially applicable for the biosynthesis of D-allulose (Tseng et al. 2014). Although AT-DAEase has been successfully applied to produce D-allulose, its high costs and low bioconversion efficiency limit its use in industrial applications (Pei et al. 2013). Immobilizing enzymes to biosynthesize products can improve their bioconversion efficiencies and reduce production process costs for the recyclability of the enzymes (Dicosimo et al. 2013). Various methods of immobilizing enzymes have been described, such as cross-linking and entrapment into particles and binding to a solid support (Franssen et al. 2013). DAEase immobilized using artificial oil bodies exhibited higher effective catalytic activity and reusability (Tseng et al. 2014). DAEases were also immobilized on graphene oxide (Dedania et al. 2017), Duolite $A 568$ beads (Lim et al. 2009), $\mathrm{Fe}_{3} \mathrm{O}_{4}$ (Patel et al. 2018), and $\mathrm{Co}_{3}\left(\mathrm{PO}_{4}\right)_{2}$ nanosheets (Zheng et al. 2018). These immobilizations improved the physical and catalytic properties. However, the activity of DAEase decreased when the cross-linker glutaraldehyde was used. The development of new materials and methods for immobilizing DAEase is urgently needed to achieve high catalytic efficiency, stability, and reusability.

Metal-organic frameworks (MOFs) have attracted tremendous interest in enzyme immobilization research owing to their ultra-high porosity, large hierarchical surface area, and excellent thermal/chemical stability (Li et al. 2016; Meshkat et al. 2020; Yogapriya and Datta 2020). Some enzymes working need harsh conditions which normally cause loss of the catalytic activity, fortunately, MOFs could enable the retention of the enzyme activity (Liang et al. 2015; Mao et al. 2020; Meshkat et al. 2020). Over the past few years, various enzymes have been successfully prepared to reduce the catalytic activity caused by harsh conditions via various methods using different MOF matrices as supports (Lian et al. 2017; Wu et al. 2015). Generally, there are four strategies for enzyme immobilization with MOFs: surface adsorption onto MOFs, covalent/coordination bonding with MOFs, coordination bonding, and de novo encapsulation (Wu et al. 2015). Among these, encapsulation of enzymes is the preferred method for synthesizing enzyme-MOF.

Zeolitic imidazolate frameworks (ZIFs) are a subfamily of MOFs with a zeolite topology in which the metal clusters are connected by imidazole linkers. In particular, ZIF- 67 has become a perfect support material because of its unique properties of different pore sizes, high surface area, cobalt transition metal, and rich $\mathrm{N}$ resources (Kaneti et al. 2017). Co-dependent nitrile hydratase (NHase) was successfully encapsulated in ZIF-67, and the synthesized NHase@ZIF-67 nanoparticles displayed significantly improved thermal stability (Pei et al. 2020). DAEase is also a co-dependent enzyme. The cobalt (II) ion (Co) is crucial for catalysis as an anchor for the substrate and can maximize the activity of DAEase through its isomerism effect (Kim et al. 2006). However, to our knowledge, the use of ZIF-67 to immobilize DAEase has not yet been reported. Furthermore, magnetic nanoparticles could enable easy separation of the biocatalyst enzyme from the reaction system using a magnet, facilitating the reusability of the catalyst (Talekar et al. 2012; Zdarta et al. 2018). Therefore, using the magnetic MOF ZIF-67 containing 
cobalt (II) ion as the scaffold to spatially co-localize and positional assemble DAEase is an efficient way to immobilize DAEase for D-allulose production.

In this study, we overexpressed the AT-DAEase enzyme in Escherichia coli (E. coli) BL21 (DE3) and immobilized the enzyme by encapsulating it into the magnetic metal-organic framework ZIF-67@ @ $\mathrm{Fe}_{3} \mathrm{O}_{4}$ for D-allulose production. First, we overexpressed and purified the enzyme AT-DAEase from the reconstituted strain and simultaneously prepared the MOF material ZIF-67@Fe $\mathrm{O}_{4}$. Then, we characterized the magnetic $\mathrm{Fe}_{3} \mathrm{O}_{4}$, MOF material ZIF-67@ $\mathrm{Fe}_{3} \mathrm{O}_{4}$, and immobilized AT-DAEase@ZIF$67 @ \mathrm{Fe}_{3} \mathrm{O}_{4}$. Finally, we evaluated the bioconversion efficiency, stability, and reusability of the immobilized AT-DAEase@ZIF-67@ $\mathrm{Fe}_{3} \mathrm{O}_{4}$ by comparing it with the free enzyme AT-DAEase.

\section{Materials And Methods}

\section{Construction of AT-DAEase expression plasmid}

The DAE gene (GenBank ID: WP_010974125.1) fragment encoding AT-DAEase from A. tumefaciens was chemically synthesized after codon optimization by Suzhou Genewiz Biological Technology Co. Ltd. (Suzhou, China). The amplified product of $870 \mathrm{bp}$ was obtained using the template of the synthesized gene and the primers (FP: 5-CGCGGATCCATGAAGCACGGCATCTACTATAG and RP:

AACTGCAGTTAACCGCCCAGCACAAAGCGG), and then cloned into a $6 \times$ His-tagged pRSFDuet- 1 vector to obtain the recombinant plasmid pRSF-DAE. A single isolated colony was picked and sent to Suzhou Genewiz Biological Technology Co. Ltd. for sequence verification.

\section{Expression and purification of recombinant protein}

After sequencing, the plasmid pRSF-DAE was transformed into E. coli BL21 (DE3) for protein production. Single isolated colonies were inoculated into $5 \mathrm{~mL}$ Terrific Broth (TB) medium (Sangon Biotech Co., Ltd., Shanghai, China) with the addition of $50 \mu \mathrm{g} / \mathrm{mL}$ kanamycin and shaken in a $220 \mathrm{rpm}$ incubator at $37^{\circ} \mathrm{C}$ overnight. The culture was transferred into $200 \mathrm{~mL}$ TB medium, induced by $0.5 \mathrm{mM}$ isopropyl-D-1thiogalactopyranoside (IPTG; Sangon Biotech Co., Ltd.) and further incubated at $18^{\circ} \mathrm{C}$ for protein expression.

After $18 \mathrm{~h}$ of induction, the cells were harvested by centrifugation at $8000 \mathrm{~g}$ for $10 \mathrm{~min}$ at $4^{\circ} \mathrm{C}$. They were resuspended in $50 \mathrm{mM}$ PBS lysis buffer $(\mathrm{pH} 7.5)$ and crushed with a high-pressure cell crusher (UnionBiotech Co., Ltd., Shanghai, China). The lysate was centrifuged at $10,000 \mathrm{~g}$ for $10 \mathrm{~min}$ at $4^{\circ} \mathrm{C}$ to obtain the supernatant. The protein was purified by loading the supernatant on a Ni-NTA agarose bead column (Invitrogen, Carlsbad, CA, USA), which was equipped with an AKTA purifier machine. The column was extensively washed with $50 \mathrm{mM}$ PBS washing buffer $(\mathrm{pH} 7.5)$ to remove unbound proteins. Finally, the protein was eluted with an elution buffer containing 75\% $50 \mathrm{mM}$ PBS and 25\% $500 \mathrm{mM}$ imidazole $(\mathrm{pH}$ 7.5). The protein was concentrated in $50 \mathrm{mM}$ PBS (pH 7.5) using a $10 \mathrm{kDa}$ ultrafilter (Merck Millipore, Darmstadt, Germany). Finally, the lysate and purity molecular mass of the recombinant protein were monitored using sodium dodecyl sulfate-polyacrylamide gel electrophoresis (SDS-PAGE). 


\section{Synthesis of $\mathrm{ZIF}-67 @ \mathrm{Fe}_{3} \mathrm{O}_{4}$ nanoparticles}

Citric acid-coated $\mathrm{Fe}_{3} \mathrm{O}_{4}$ nanoparticles were prepared according to a previously published method (Liu et al. 2009). To obtain ZIF-67@ $\mathrm{Fe}_{3} \mathrm{O}_{4}$ nanoparticles, $500 \mathrm{mg}$ of citric acid-coated $\mathrm{Fe}_{3} \mathrm{O}_{4}$ nanoparticles were dispersed in $10 \mathrm{~mL}$ of $10 \mathrm{mM} \mathrm{Co}\left(\mathrm{NO}_{3}\right)_{2} \cdot 6 \mathrm{H}_{2} \mathrm{O}$ (Aladdin Chemistry Co., Ltd. Shanghai, China) and then washed with $10 \mathrm{~mL}$ of deionized water. The reaction system was mechanically stirred at $1000 \mathrm{~g}$ and $25^{\circ} \mathrm{C}$ for $1 \mathrm{~h}$, after which the $\mathrm{Co}^{2+} @ \mathrm{Fe}_{3} \mathrm{O}_{4}$ product was thoroughly washed with water and separated by a magnet. The $\mathrm{Co}^{2+} @ \mathrm{Fe}_{3} \mathrm{O}_{4}$ nanoparticles were then re-dispersed in $10 \mathrm{~mL}$ of water, followed by the addition of $10 \mathrm{~mL}$ of $20 \mathrm{mM}$ 2-MeIM (Aladdin Chemistry Co.). To obtain the ZIF-67@Fe $\mathrm{O}_{4}$ nanoparticles, the mixture was mechanically stirred at $1000 \mathrm{~g}$ and $25^{\circ} \mathrm{C}$ for $1 \mathrm{~h}$. The $\mathrm{ZIF}-67 @ \mathrm{Fe}_{3} \mathrm{O}_{4}$ nanoparticles were washed with methanol and water twice and then air-dried at $60^{\circ} \mathrm{C}$ for $12 \mathrm{~h}$.

\section{Immobilization of AT-DAEase on ZIF-67@Fe $\mathrm{O}_{4}$ nanoparticles}

To prepare the AT-DAEase@ZIF-67@Fe $\mathrm{O}_{3} \mathrm{O}_{4}$ nanoparticles, AT-DAEase was immobilized in the ZIF-67 shell by mixing $50 \mathrm{mg}$ of ZIF-67@ $\mathrm{Fe}_{3} \mathrm{O}_{4}$ nanoparticles with $1 \mathrm{~mL}$ of a solution containing $10 \mathrm{mg}$ $\mathrm{Co}\left(\mathrm{NO}_{3}\right)_{2} \cdot 6 \mathrm{H}_{2} \mathrm{O}, 8 \mathrm{mg}$ 2-methylimidazole (MelM), and $2 \mathrm{mg}$ AT-DAEase. The samples were mechanically stirred at $1000 \mathrm{~g}$ and $4^{\circ} \mathrm{C}$ for $1 \mathrm{~h}$ to produce AT-DAEase@ZIF-67@ $\mathrm{Fe}_{3} \mathrm{O}_{4}$. The product was washed with water and separated using a magnet. Protein concentrations were measured using the Bradford reagent (Bio-Rad, Hercules, CA, USA).

\section{Calculation of enzyme loading}

The enzyme loading (Q) of the enzyme nanoparticles was calculated (Hammes and Wu, 1971) as:

$$
\mathrm{Q}=\frac{(\mathrm{C} \square-\mathrm{C}) V}{m}
$$

where $C_{0}(\mathrm{mg} / \mathrm{mL})$ is the initial enzyme concentration without immobilization, $C(\mathrm{mg} / \mathrm{mL})$ is the final enzyme concentration of the supernatant after immobilization, $m(\mathrm{mg})$ is the dry weight of ZIF-67@ @ $\mathrm{Fe}_{3} \mathrm{O}_{4}$ nanoparticles added to the enzyme immobilization system, and $V(\mathrm{~mL})$ is the volume of the added enzyme solution.

\section{Characterization of $\mathrm{Fe}_{3} \mathrm{O}_{4}$, ZIF-67@Fe $\mathrm{O}_{4}$, and AT- DAEase@ZIF-67@Fe $\mathrm{O}_{4}$}

The magnetic nanoparticles were imaged by scanning electron microscopy (SEM) using a su1510 field emission microscope (Hitachi, Tokyo, Japan). The structural and chemical properties of the magnetic nanoparticles were also analyzed by Fourier transform infrared spectroscopy (FTIR) using a Nicolet iS50 (Thermo Fisher Scientific, Waltham, MA, USA). Thermal gravimetric analysis (TGA) was performed using 
an 1100SF (Mettler, Switzerland). They were detected in the temperature range of $25-750^{\circ} \mathrm{C}$ with a temperature increase at a rate of $10^{\circ} \mathrm{C} / \mathrm{min}$ under a nitrogen flow rate of $20 \mathrm{~mL} / \mathrm{min}$.

\section{AT-DAEase activity analysis}

The production of $1 \mu \mathrm{mol}$ D-allulose within $1 \mathrm{~min}$ from D-fructose under some assay conditions is defined as one unit of enzyme activity. The specific activity is expressed as enzyme units per milligram of protein. In the assay, free AT-DAEase catalyzed D-fructose to D-allulose in $50 \mathrm{mM}$ sodium phosphate buffer (pH 7.5) with $0.1 \mathrm{M} \mathrm{Co}^{2+}$ and without $\mathrm{Co}^{2+}$. The AT-DAEase@ZIF-67@Fe $\mathrm{O}_{4}$ catalyst was in the same buffer ( $\mathrm{pH}$ 8.0) without $\mathrm{Co}^{2+}$. The bioconversion rates of D-fructose to D-allulose were determined using $50 \mathrm{~g} / \mathrm{L}$ D-fructose (Aladdin Chemistry Co., Ltd.) as the substrate and $0.6 \mu \mathrm{M}$ enzyme as the catalyst under the assay conditions of $50^{\circ} \mathrm{C}$ and $55^{\circ} \mathrm{C}$ for $5 \mathrm{~min}$. The reaction was stopped by boiling the mixture for $10 \mathrm{~min}$.

The D-allulose product and D-fructose substrate in the supernatant were detected using a highperformance liquid chromatography (HPLC) system equipped with a RID-20A refractive index detector (Shimadzu, Kyoto, Japan), an injector (Shimadzu), and a Sugar-Pak I column (Shimadzu; $30 \mathrm{~mm} \times 5 \mathrm{~mm}$ i.d.). The column was eluted with deionized water as the mobile phase at a flow rate of $0.4 \mathrm{~mL} / \mathrm{min}$ and $85^{\circ} \mathrm{C}$. The samples $(20 \mu \mathrm{L})$ were injected into the column. The retention times of D-fructose and Dallulose were determined using $17.02 \mathrm{~min}$ and $24.07 \mathrm{~min}$ standards, respectively.

\section{Optimal temperature, thermal stability, and $\mathrm{pH}$ of free AT- DAEase and AT-DAEase@ZIF-67@ $\mathrm{Fe}_{3} \mathrm{O}_{4}$}

To determine the optimal reaction temperature, the activities of free AT-DAEase and AT-DAEase@ZIF$67 @ \mathrm{Fe}_{3} \mathrm{O}_{4}$ were measured at temperatures ranging from $45-70^{\circ} \mathrm{C}$. The mixed samples were incubated for 5 min and activity was determined. The thermal stability of free AT-DAEase and AT-DAEase@ZIF$67 @ \mathrm{Fe}_{3} \mathrm{O}_{4}$ was characterized by incubating the enzyme mixture at $55^{\circ} \mathrm{C}$ in $50 \mathrm{mM}$ sodium phosphate buffer ( $\mathrm{pH} 7.5$ ). The mixture was sampled at $0,20,40,60,80,100,120,240$, and $360 \mathrm{~min}$, and the residual enzyme activities of the samples were also measured. The effect of $\mathrm{pH}$ on the enzyme activities of AT-DAEase@ZIF-67@Fe $\mathrm{O}_{4}$ was determined by incubating the reaction mixture of 50 mM sodium phosphate buffer with $50 \mathrm{~g} / \mathrm{L}$ D-fructose in the $\mathrm{pH}$ rang of 7.0-9.0. The mixtures were incubated at $55^{\circ} \mathrm{C}$ and $\mathrm{pH} 7.0,7.5,8.0,8.5$, and 9.0, respectively, for $5 \mathrm{~min}$, and then the activities were measured.

\section{Reusability of AT-DAEase@ZIF-67@Fe $\mathrm{O}_{4}$}

The reusability of AT-DAEase@ZIF-67@Fe $\mathrm{O}_{4}$ was determined by incubating the mixture with the immobilized enzyme and $50 \mathrm{~g} / \mathrm{L}$ D-fructose dissolved in $50 \mathrm{mM}$ sodium phosphate buffer (pH 8.0) at $55^{\circ} \mathrm{C}$ for $5 \mathrm{~min}$. After the reaction, the immobilized enzyme was recovered using a magnet, and the supernatant was collected by centrifugation. The amounts of D-fructose and D-allulose were analyzed using HPLC. AT-DAEase@ZIF-67@Fe $\mathrm{O}_{4}$ particles were washed three times with sodium phosphate buffer and reused for the next cycle. This procedure was repeated eight times. The reusability of AT- 
DAEase@ZIF-67@Fe $\mathrm{O}_{4}$ was analyzed through the activity of AT-DAEase@ZIF-67@Fe $\mathrm{O}_{3} \mathrm{O}_{4}$ after every cycle.

\section{Results}

\section{Expression, purification and characterization of AT-DAEase}

We inserted the DNA fragment encoding AT-DAEase into the $6 \times$ His-tagged vector pRSFDuet- 1 to construct the plasmid pRSF-DAE to express AT-DAEase. We transformed the plasmid pRSF-DAE into $E$. coli BL21 (DE3) to obtain the recombinant strain and cultured it for expression. After induction with IPTG at $18^{\circ} \mathrm{C}$ and SDS-PAGE analysis, the soluble AT-DAEase protein was identified in the supernatant of the cell lysate of the recombinant $E$. coli following centrifugation (Figure 1A, lane a). To verify and characterize the enzyme, it was purified the using the AKTA system. SDS-PAGE revealed a band of purified protein with an approximate molecular mass of $32 \mathrm{kDa}$, representing AT-DAEase subunits (Figure $1 \mathrm{~A}$, lane $\mathrm{b})$.

A catalysis experiment was performed using purified free AT-DAEase. The bioconversion ratio reached approximately $32 \%$ under the optimal conditions of $50^{\circ} \mathrm{C}$ and $\mathrm{pH} 7.5$ (Figure 1B), as previously reported (Kim et al. 2006). The bioconversion ratio was approximately $35 \%$ higher when $\mathrm{Co}^{2+}$ was present in the reaction system than that without $\mathrm{Co}^{2+}$. The specific activities of free AT-DAEase reached approximately $55 \mathrm{U} \mathrm{mg}^{-1}$ and $63 \mathrm{U} \mathrm{mg}^{-1}$ when the reaction system did not contain $\mathrm{Co}^{2+}$ and with $0.1 \mathrm{M} \mathrm{Co}^{2+}$, respectively.

\section{Design strategy of immobilizing AT-DAEase into ZIF- 67@ $\mathrm{Fe}_{3} \mathrm{O}_{4}$}

The design strategy for immobilizing AT-DAEase into ZIF-67@Fe $\mathrm{O}_{4}$ is shown in Figure 2. We obtained the enzyme AT-DAEase from the recombinant $E$. coli BL21 (DE3) strain after expression and purification. Citric acid-coated magnetic $\mathrm{Fe}_{3} \mathrm{O}_{4}$ nanoparticles were prepared using a solvothermal reaction, including the reduction of $\mathrm{FeCl}_{3}$ by trisodium citrate in ethylene glycol. We chose ZIF-67 to immobilize DAEase because of its different pore sizes, high surface area, transition metal $\mathrm{Co}$, and rich $\mathrm{N}$ resources (Kaneti et al. 2017). These properties of ZIF-67 could potentially improve the thermal stability of DAEase and provide the essential metal iron $\mathrm{Co}^{2+}$, which plays a crucial role in DAEase catalysis by anchoring the substrate. Furthermore, using ZIF-67 to immobilize DAEase facilitated the formation of chemical bonds between $\mathrm{Co}^{2+}$ and the enzyme, and simplified the process of preparation of the reaction system and purification of the product. Therefore, citric acid-coated $\mathrm{Fe}_{3} \mathrm{O}_{4}$ nanoparticles were self-assembled with $\mathrm{Co}\left(\mathrm{NO}_{3}\right)_{2} \cdot 6 \mathrm{H}_{2} \mathrm{O}$ and 2-MelM individually to generate ZIF-67@ @ $\mathrm{Fe}_{3} \mathrm{O}_{4}$ nanoparticles. Finally, we encapsulated the enzyme AT-DAEase into the ZIF-67@ $\mathrm{Fe}_{3} \mathrm{O}_{4}$ nanoparticles by fixing the ZIF-67 shell, $\mathrm{Co}\left(\mathrm{NO}_{3}\right)_{2} \cdot 6 \mathrm{H}_{2} \mathrm{O}$, and 2-MelM. 


\section{Characterization of $\mathrm{Fe}_{3} \mathrm{O}_{4}, \mathrm{ZIF-67@Fe} \mathrm{O}_{4}$ and AT- DAEase@ZIF-67@Fe $\mathrm{O}_{4}$}

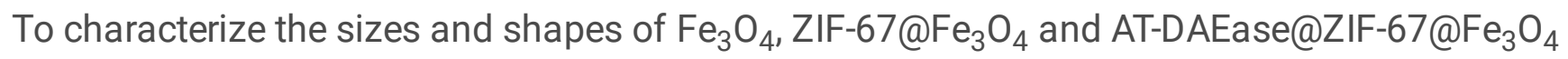
nanoparticles, they were imaged using SEM. As shown in Figure 3A, the average diameter of the spherical $\mathrm{Fe}_{3} \mathrm{O}_{4}$ magnetic nanoparticles was $232 \mathrm{~nm}$. As shown in Figure 3B, co-precipitation successfully generated a ZIF-67 shell with an average thickness of $12 \mathrm{~nm}$ on the surface of the $\mathrm{Fe}_{3} \mathrm{O}_{4}$ nanoparticles. The ZIF-67@ $\mathrm{Fe}_{3} \mathrm{O}_{4}$ nanoparticles were well dispersed, and their shapes did not change significantly. However, the particle sizes significantly increased compared to that of $\mathrm{Fe}_{3} \mathrm{O}_{4}$. SEM images revealed the successful creation of MOF nanoparticle aggregates and the changes in the shapes and sizes of the ATDAEase@ZIF-67@Fe $\mathrm{O}_{4}$ nanoparticles (Figure 3C).

To confirm the attachment of the MOF and the enzyme, FTIR spectral analysis was performed. Figure 4A

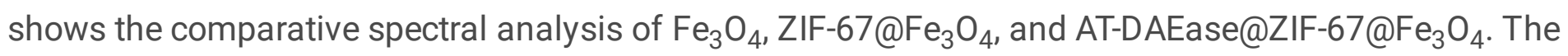
absorption band centered at $1610 \mathrm{~cm}^{-1}$ in the sample $\mathrm{Fe}_{3} \mathrm{O}_{4}$ (black line) represents the $\mathrm{C}=0$ stretching vibrations of the citric acid groups coating on $\mathrm{Fe}_{3} \mathrm{O}_{4}$. Comparison of $\mathrm{Fe}_{3} \mathrm{O}_{4}$ with $\mathrm{ZIF-67@Fe} \mathrm{O}_{4}$ revealed that the bands in the range of $600-1500 \mathrm{~cm}^{-1}$ were attributed to the characteristic stretching and bending modes of the imidazole ring of 2-MeIM. The FTIR spectrum of AT-DAEase@ZIF-67@Fe $\mathrm{O}_{4}$ displayed two absorption bands at 1635 and $3250 \mathrm{~cm}^{-1}$ compared to that of ZIF-67@ $\mathrm{Fe}_{3} \mathrm{O}_{4}$.

To further confirm the attachment of the MOF and the enzyme, TGA plots were also obtained. They revealed that the magnetic $\mathrm{Fe}_{3} \mathrm{O}_{4}$ nanoparticles lost $7.1 \%$ of their weight at $370^{\circ} \mathrm{C}$, corresponding to the removal of water and citric acid functionalities (Figure 4B). The ZIF-67@Fe $\mathrm{O}_{4}$ nanoparticles lost an initial weight of approximately $15 \%$ within the range of $150-260^{\circ} \mathrm{C}$, which was related to the removal of guest water molecules and unreacted ligands in the pores. The second weight loss of $29.6 \%$ was observed between 450 and $550^{\circ} \mathrm{C}$ due to the decomposition of ZIF-67. The residual $51.2 \%$ of the weight was cobalt and iron. For AT-DAEase@ZIF-67@Fe $\mathrm{O}_{3}$ nanoparticles, the curve showed an initial weight loss of approximately $20 \%$ that was related to the removal of the guest molecules, including enzymes, at temperatures ranging from 150 to $260^{\circ} \mathrm{C}$.

\section{AT-DAEase enzyme load and specific activity detection}

The enzyme loading and specific activities are summarized in Table 1. The enzyme loading was $37 \mathrm{mg}$ enzyme per gram of $\mathrm{Fe}_{3} \mathrm{O}_{4}$ nanoparticles, which was consistent with the TGA results. The ATDAEase@ZIF-67@ $\mathrm{Fe}_{3} \mathrm{O}_{4}$ nanoparticles showed the highest activity of $65.1 \mathrm{U} \mathrm{mg}^{-1}$, which was $18 \%$ higher than that of free AT-DAEase. To detect the bioconversion rate of $D$-fructose to $D$-allulose by ATDAEase@ZIF-67@ $\mathrm{Fe}_{3} \mathrm{O}_{4}$, we performed an epimerization reaction using the free enzymes AT-DAEase and AT-DAEase@ZIF-67@ $\mathrm{Fe}_{3} \mathrm{O}_{4}$ under optimal reaction conditions ( $\mathrm{pH} 8.0$ and temperature of $55^{\circ} \mathrm{C}$ ). The free AT-DAEase showed a higher bioconversion ratio of $35.4 \%$ when $\mathrm{Co}^{2+}$ was added to the reaction mixture 
than that without $\mathrm{Co}^{2+}$. AT-DAEase@ZIF-67@ $\mathrm{Fe}_{3} \mathrm{O}_{4}$ had a higher bioconversion ratio than the free ATDAEase with or without $\mathrm{Co}^{2+}$ in the reaction mixture. At equilibrium, the bioconversion ratio of $D$-fructose to D-allulose was $38.1 \%$, which was $18.6 \%$ higher than that of AT-DAEase without $\mathrm{Co}^{2+}$.

Table 1

Bioconversion ratio, speceific activities and enzyme loading capacities of free AT-DAEase, free ATDAEase+Co ${ }^{2+}$ and AT-DAEase@ZIF-67@Fe $\mathrm{O}_{4}$

\begin{tabular}{|llll|}
\hline & $\begin{array}{l}\text { Bioconversion } \\
\text { ratio (\%) }\end{array}$ & $\begin{array}{l}\text { Specific activity }(\mathrm{U} \\
\left.\mathbf{m g}^{-1}\right)\end{array}$ & $\begin{array}{l}\text { Enzyme loading capacity (mg per } \\
\left.\mathbf{g ~ F e}_{3} \mathbf{O}_{\mathbf{4}}\right)\end{array}$ \\
\hline free AT-DAEase & 32.1 & 55.3 & - \\
\hline $\begin{array}{l}\text { free AT- } \\
\text { DAEase+Co2+ }\end{array}$ & 35.4 & 63.9 & - \\
\hline $\begin{array}{l}\text { AT-DAEase@ZIF- } \\
\text { 67@Fe } \mathrm{O}_{4}\end{array}$ & 38.1 & 65.1 & 37 \\
\hline
\end{tabular}

\section{Thermal stability of MOF-immobilized AT-DAEase@ZIF- $67 @ \mathrm{Fe}_{3} \mathrm{O}_{4}$}

Thermal stability is an essential requirement for industrial enzymes because the reaction at higher temperatures can increase the bioconversion rate and reactant solubility, and reduce the risk of contamination during bio-catalytic processes. To study the thermal stability of the MOF-immobilized ATDAEase@ZIF-67@ $\mathrm{Fe}_{3} \mathrm{O}_{4}$, we measured the relative enzyme activities of the temperature profile from $45^{\circ} \mathrm{C}$ to $70^{\circ} \mathrm{C}$ with D-fructose as a substrate. AT-DAEase@ZIF-67@ $\mathrm{Fe}_{3} \mathrm{O}_{4}$ exhibited a higher level of activity than free AT-DAEase over the entire temperature range (Figure 5A). The maximum activities of free AT-DAEase and AT-DAEase@ZIF-67@ $\mathrm{Fe}_{3} \mathrm{O}_{4}$ were observed at $50^{\circ} \mathrm{C}$ and $55^{\circ} \mathrm{C}$, respectively, indicating that immobilization increased the optimal temperature of free AT-DAEase. The enzyme activity of almost all the reactions of AT-DAEase@ZIF-67@ $@ \mathrm{Fe}_{3} \mathrm{O}_{4}$ surpassed $80 \%$ at temperatures from $45^{\circ} \mathrm{C}$ to $70^{\circ} \mathrm{C}$, while that of only the optimal temperature reaction of free AT-DAEase was comparable (Figure $5 \mathrm{~A}$ ).

We also detected the residual activities of free AT-DAEase and AT-DAEase@ZIF-67@Fe $\mathrm{O}_{3} \mathrm{O}_{4}$ reacting at $55^{\circ} \mathrm{C}$ from 60 to $360 \mathrm{~min}$. The residual activity of AT-DAEase@ZIF-67@ $\mathrm{Fe}_{3} \mathrm{O}_{4}$ remained above $80 \%$ after $360 \mathrm{~min}$, while it decreased to almost zero after $120 \mathrm{~min}$ in the free AT-DAEase reaction system (Figure 5B). These results indicate that the thermal stability of the MOF-immobilized AT-DAEase@ZIF-67@Fe $\mathrm{O}_{4}$ was better than that of the free AT-DAEase.

\section{Effect of pH on AT-DAEase@ZIF-67@Fe $\mathrm{O}_{4}$ and free AT- DAEase activities}


$\mathrm{pH}$ stability is another key factor affecting the enzyme activity of AT-DAEase, and is an important operational factor for industrial enzymes. To investigate the effect of $\mathrm{pH}$ on the conversion of $\mathrm{D}$-fructose to D-allulose, we measured the activity of free AT-DAEase and AT-DAEase@ZIF-67@Fe $\mathrm{O}_{3} \mathrm{O}_{4}$ at pH values of 7.0, 7.5, 8.0, 8.5, and 9.0. The optimum pH was 7.5 for free AT-DAEase and 8.0 for AT-DAEase@ZIF$67 @ \mathrm{Fe}_{3} \mathrm{O}_{4}$ (Figure 5C). In general, AT-DAEase@ZIF-67@Fe $\mathrm{O}_{4}$ activities over the pH range were higher than activities of the free AT-DAEase. AT-DAEase@ZIF-67@Fe $\mathrm{O}_{4}$ retained $>80 \%$ activity at pH 7.0-9.0, while free AT-DAEase displayed $<70 \%$ activity, except at $\mathrm{pH} 7.5$. The findings indicate the significant advantage of AT-DAEase@ZIF-67@Fe $\mathrm{F}_{3}$ over the free AT-DAEase in pH stability of the enzyme.

\section{Reusability of AT-DAEase@ZIF-67@Fe $\mathrm{O}_{4}$}

Immobilized enzymes can be recycled, which can reduce the cost of production in bio-catalytic processes for industrial applications. This is a key reason favoring the use of immobilized enzymes in industrial applications. ZIF-67@Fe $\mathrm{F}_{3} \mathrm{O}_{4}$ immobilized AT-DAEase can be easily recovered from the reaction mixture system using magnetic attraction. To evaluate the feasibility of recovery and recycling of ATDAEase@ZIF-67@F $\mathrm{Fe}_{3} \mathrm{O}_{4}$, the relative activities were determined during eight consecutive rounds of the bioconversion of D-fructose to D-allulose at pH 8.0 and $55^{\circ} \mathrm{C}$. AT-DAEase@ZIF-67@F $\mathrm{C}_{3} \mathrm{O}_{4}$ retained $>45 \%$ of its initial activity after eight cycles of enzyme use (Figure 5D).

\section{Discussion}

In the present study, AT-DAEase was successfully encapsulated into the ZIF-67@Fe $\mathrm{O}_{4}$ magnetic hybrid MOF using a self-assembly strategy. A prior study described the immobilization of $D$-allulose 3-epimerase from $C$. cellulolyticum on artificial oil bodies with the aim of decreasing the cost of $D$-allulose production (Tseng et al. 2014). In contrast, we anchored Co on MOF ZIF67 to facilitate the catalytic reaction of the Co-dependent enzyme AT-DAEase, with magnetic $\mathrm{Fe}_{3} \mathrm{O}_{4}$ as the carrier of the catalyst. This design omitted the addition of Co to the reaction system and simplified the separation of the catalyst and its recycling. SEM imaging clearly demonstrated the changes in the shapes and sizes of the AT-DAEase@ZIF$67 @ \mathrm{Fe}_{3} \mathrm{O}_{4}$ nanoparticles. In the FTIR spectral analysis, the two bands at 1635 and $3250 \mathrm{~cm}^{-1}$ were attributed to the $\mathrm{C}=\mathrm{O}$ stretching vibration and $\mathrm{N}-\mathrm{H}$ stretching vibration of the amide group, respectively, confirming that AT-DAEase was immobilized on ZIF-67@ $\mathrm{Fe}_{3} \mathrm{O}_{4}$. TGA plot analysis demonstrated a weight loss that was generally consistent with the removal of all molecules at temperatures ranging from 25 to $750^{\circ} \mathrm{C}$. The weight percentage of AT-DAEase was approximately $5 \%$ in ZIF-67. The FTIR spectral analysis and TGA plots confirmed the successful formation of the ZIF-67@Fe $\mathrm{F}_{3}$ core-shell structures.

AT-DAEase@ZIF-67@Fe $\mathrm{O}_{3}$ displayed high catalytic activity for D-fructose to D-allulose, and its specific activity reached to $65.1 \mathrm{U} \mathrm{mg}^{-1}$. The higher bioconversion ratio of AT-DAEase@ZIF-67@Fe $\mathrm{F}_{3} \mathrm{O}_{4}$ than that of free AT-DAEase suggests that the ZIF-67@ $\mathrm{Fe}_{3} \mathrm{O}_{4} \mathrm{MOF}$ improves the bioconversion efficiency of the ATDAEase enzyme. The synthesized AT-DAEase@ZIF-67@Fe $\mathrm{O}_{3} \mathrm{O}_{4}$ displayed a significant improvement in thermal stability compared to the free enzyme AT-DAEase. This indicated that the MOF material enabled 
the enzyme to resist high temperatures. The collective results suggest that adding $\mathrm{Co}^{2+}$ to the reaction mixture can increase the bioconversion rate, consistent with previous reports (Kim et al. 2006; Tseng et al. 2014). In addition, AT-DPEase@ZIF-67@ $\mathrm{Fe}_{3} \mathrm{O}_{4}$ displayed an improved bioconversion efficiency compared to that of free AT-DPEase with $\mathrm{Co}^{2+}$. The increased thermal stability of the immobilized AT-DPEase may have led to an improvement in the bioconversion efficiency. The optimal conditions for maximum enzyme activity of AT-DAEase@ZIF-67@Fe $\mathrm{O}_{3} \mathrm{O}_{4}$ were $55^{\circ} \mathrm{C}$ and pH 8.0. The optimal temperature and pH of free ATDAEase were $50^{\circ} \mathrm{C}$ and 7.5 , respectively. The improved optimal temperature should benefit from modification of the MOF material. The mechanism of the optimal pH property shifting is unclear. The residual activity remained above $80 \%$ of the maximum activity at high temperatures ranging from 55$70^{\circ} \mathrm{C}$ and a pH range of 7.0-9.0. These results are consistent with those of previous studies reporting that the MOF coating could protect enzymes from adverse conditions and enhance their stability (Tseng et al. 2014; Pei et al. 2020). When AT-DAEase was immobilized with graphene oxide, the optimal pH was 7.5, the optimal temperature was $60^{\circ} \mathrm{C}$, and the biotransformation ratio reached $40 \%$, but the enzyme activity after eight cycles of use remained at approximately $25 \%$ (Dedania et al. 2017). In the present study, ATDAEase@ZIF-67@Fe $\mathrm{F}_{3} \mathrm{O}_{4}$ could be reused for eight cycles with enzyme activity remaining at $>45 \%$ of its initial activity. Therefore, our enzyme modification method appears to be more suitable for recycling.

Moreover, AT-DAEase@ZIF-67@Fe $\mathrm{O}_{3}$ had a slightly higher bioconversion rate than that of the free enzyme AT-DAEase, which may be related to the increases in optimal temperature and $\mathrm{pH}$. The magnetic ZIF-67 scaffold could enable separation of the enzyme from the reaction system using a magnet, facilitating the reuse of the catalyst (Talekar et al. 2012; Zdarta et al. 2018). In the present study, ATDAEase@ZIF-67@ $\mathrm{Fe}_{3} \mathrm{O}_{4}$ could be reused multiple times if used under optimal conditions. Therefore, immobilization of the enzyme could reduce the often high cost of industrial applications of enzymes. ZIF67@ $\mathrm{Fe}_{3} \mathrm{O}_{4}$-immobilized AT-DAEase has potential applications in the production of D-allulose at a lower cost than the free enzyme. Therefore, the Co-based magnetic hybrid ZIF-67@Fe $\mathrm{F}_{3} \mathrm{O}_{4}$ is a suitable host matrix for immobilizing Co-dependent AT-DAEase for the large-scale industrial preparation of D-allulose.

\section{Declarations}

\section{Ethical Statement}

This article does not contain any studies with human participants performed by any of the authors.

\section{Funding}

This work was supported by the Natural Science Foundation of Jiangsu Province (BK20190610) and the 111 Project (111-2-06).

Data availability: All data generated or analyzed during this study are included in this published article.

\section{References}


1. Tseng CW, Liao CY, Sun Y, Peng CC, Tzen JT, Guo RT, Liu JR (2014) Immobilization of Clostridium cellulolyticum D-psicose 3-epimerase on artificial oil bodies. J Agric Food Chem 62(28):6771-6776. https://doi.org/10.1021/jf502022w

2. Matsuo T, Suzuki H, Hashiguchi M, Izumori K (2002) D-psicose is a rare sugar that provides no energy to growing rats. J Nutr Sci Vitaminol 48(1):77-80. https://doi.org/10.3177/jnsv.48.77

3. Sun Y, Hayakawa S, Ogawa M, Fukada K, Izumori K (2008) Influence of a rare sugar, d-psicose, on the physicochemical and functional properties of an aerated food system containing egg albumen. $J$ Agric Food Chem 56(12):4789-4796. https://doi.org/10.1021/jf800050d

4. Zhang W, Fang D, Xing Q, Zhou L, Jiang B, Mu W (2013) Characterization of a novel metal-dependent D-psicose 3-epimerase from Clostridium scindens 35704. PLoS ONE 8(4):e62987. https://doi.org/10.1371/journal.pone.0062987

5. Patel SN, Singh V, Sharma M, Sangwan RS, Singhal NK, Singh SP (2018) Development of a thermostable and recyclable magnetic nanobiocatalyst for bioprocessing of fruit processing residues and Dallulose synthesis. Bioresour Technol 247:633-639. https://doi.org/10.1016/j.biortech.2017.09.112

6. Sheldon RA, Woodley JM (2018) Role of biocatalysis in sustainable chemistry. Chem Rev 118(2):801-838. https://doi.org/10.1021/acs.chemrev.7b00203

7. Kim K, Kim HJ, Oh DK, Cha SS, Rhee S (2006) Crystal structure of d-psicose 3-epimerase from Agrobacterium tumefaciens and its complex with true substrate d-fructose: a pivotal role of metal in catalysis, an active site for the non-phosphorylated substrate, and its conformational changes. $\mathrm{J} \mathrm{Mol}$ Biol 361(5):920-931. https://doi.org/10.1016/j.jmb.2006.06.069

8. Zdarta J, Meyer A, Jesionowski T, Pinelo M (2018) A general overview of support materials for enzyme immobilization: characteristics, properties, practical utility. Catalysts 8(2):92. https://doi.org/10.3390/catal8020092

9. Itoh H, Okaya H, Khan AR, Tajima S, Hayakawa S, Izumori K (1994) Purification and characterization of D-tagatose 3-epimerase from Pseudomonas sp. ST-24. Biosci Biotech Bioch 58(12):2168-2171. https://doi.org/10.1271/bbb.58.2168

10. Kim HJ, Hyun EK, Kim YS, Lee YJ, Oh DK (2006) Characterization of an Agrobacterium tumefaciens d-psicose 3-epimerase that converts d-fructose to d-psicose. Appl Environ Microbiol 72(2):981-985. https://doi.org/10.1128/AEM.72.2.981-985.2006

11. Mu W, Chu F, Xing Q, Yu S, Zhou L, Jiang B (2011) Cloning, expression, and characterization of a dpsicose 3-epimerase from Clostridium cellulolyticum H10. J Agric Food Chem 59(14):7785-7792. https://doi.org/10.1021/jf201356q

12. Zhu Y, Men Y, Bai W, Li X, Zhang L, Sun Y, Ma Y (2012) Overexpression of d-psicose 3-epimerase from Ruminococcus sp. in Escherichia coli and its potential application in d-psicose production. Biotechnol Lett 34(10):1901-1906. https://doi.org/10.1007/s10529-012-0986-4

13. Patel SN, Kaushal G, Singh SP (2021) D-Allulose 3-epimerase of Bacillus sp. origin manifests profuse heat-stability and noteworthy potential of D-fructose epimerization. Microb Cell Fact 20(1):60. https://doi.org/10.1186/s12934-021-01550-1 
14. Patel SN, Kaushal G, Singh SP (2020) A novel d-allulose 3-epimerase gene from the metagenome of a thermal aquatic habitat and d-allulose production by bacillus subtilis whole-cell catalysis. Appl Environ Microbiol 86(5):e02605-e02619. https://doi.org/10.1128/AEM.02605-19

15. Pei X, Zhang H, Meng L, Xu G, Yang L, Wu J (2013) Efficient cloning and expression of a thermostable nitrile hydratase in Escherichia coli using an auto-induction fed-batch strategy. Process Biochem 48(12):1921-1927. https://doi.org/10.1016/j.procbio.2013.09.004

16. Dicosimo R, Mcauliffe JC, Poulose AJ, Bohlmann G (2013) Industrial use of immobilized enzymes. Chem Soc Rev 42(15):6437-6474. https://doi.org/10.1039/C3CS35506C

17. Franssen MC, Steunenberg P, Scott EL, Zuilhof H, Sanders JP (2013) Immobilised enzymes in biorenewables production. Chem Soc Rev 42(15):6491-6533. https://doi.org/10.1039/C3CS00004D

18. Dedania SR, Patel MJ, Patel DM, Akhani RC, Patel DH (2017) Immobilization on graphene oxide improves the thermal stability and bioconversion efficiency of D-psicose 3-epimerase for rare sugar production. Enzyme Microb Technol 107:49-56. https://doi.org/10.1016/j.enzmictec.2017.08.003

19. Lim B, Kim H, Oh D (2009) A stable immobilized D-psicose 3-epimerase for the production of Dpsicose in the presence of borate. Process Biochem 44(8):822-828. https://doi.org/10.1016/j.procbio.2009.03.017

20. Zheng L, Sun Y, Wang J, Huang H, Geng X, Tong Y, Wang Z (2018) Preparation of a flower-like immobilized d-psicose 3-epimerase with enhanced catalytic performance. Catalysts 8(10):468. https://doi.org/10.3390/catal8100468

21. Li P, Moon SY, Guelta MA, Harvey SP, Hupp JT, Farha OK (2016) Encapsulation of a nerve agent detoxifying enzyme by a mesoporous zirconium metal-organic framework engenders thermal and long-term stability. J Am Chem Soc 138(26):8052-8055. https://doi.org/10.1021/jacs.6b03673

22. Meshkat S, Kaliaguine S, Rodrigue D (2020) Comparison between ZIF-67 and ZIF-8 in Pebax® MH1657 mixed matrix membranes for $\mathrm{CO}_{2}$ separation. Sep Purif Technol 235:116150-116150. https://doi.org/10.1016/j.seppur.2019.116150

23. Yogapriya R, Datta KKR (2020) Porous fluorinated graphene and ZIF-67 composites with hydrophobic-oleophilic properties towards oil and organic solvent sorption. J Nanosci Nanotechnol 20(5):2930-2938. https://doi.org/10.1166/jnn.2020.17465

24. Liang K, Ricco R, Doherty CM, Styles MJ, Bell S, Kirby N, Mudie S, Haylock D, Hill AJ, Doonan CJ, Falcaro P (2015) Biomimetic mineralization of metal-organic frameworks as protective coatings for biomacromolecules. Nat Commun 6:7240. https://doi.org/10.1038/ncomms8240

25. Mao S, Cheng X, Zhu Z, Chen Y, Li C, Zhu M, Liu X, Lu F, Qin HM (2020) Engineering a thermostable version of $\mathrm{D}$-allulose 3-epimerase from Rhodopirellula baltica via site-directed mutagenesis based on B-factors analysis. Enzyme Microb Technol 132:109441. https://doi.org/10.1016/j.enzmictec.2019.109441

26. Lian X, Fang Y, Joseph E, Wang Q, Li J, Banerjee S, Lollar C, Wang X, Zhou HC (2017) Enzyme-MOF (metal-organic framework) composites. Chem Soc Rev 46(11):3386-3401. https://doi.org/10.1039/C7CS00058H 
27. Wu X, Yang C, Ge J, Liu Z (2015) Polydopamine tethered enzyme/metal-organic framework composites with high stability and reusability. Nanoscale 7(45):18883-18886.

https://doi.org/10.1039/c5nr05190h

28. Kaneti YV, Dutta S, Hossain MSA, Shiddiky MJA, Tung KL, Shieh FK, Tsung CK, Wu KC, Yamauchi Y (2017) Strategies for improving the functionality of zeolitic imidazolate frameworks: tailoring nanoarchitectures for functional applications. Adv Mater 29(38):1700213.

https://doi.org/10.1002/adma.201700213

29. Pei X, Wu Y, Wang J, Chen Z, Liu W, Su W, Liu F (2020) Biomimetic mineralization of nitrile hydratase into a mesoporous cobalt-based metal-organic framework for efficient biocatalysis. Nanoscale 12(2):967-972. https://doi.org/10.1039/c9nr06470b

30. Talekar S, Ghodake V, Ghotage T, Rathod P, Deshmukh P, Nadar S, Mulla M, Ladole M (2012) Novel magnetic cross-linked enzyme aggregates (magnetic CLEAs) of alpha amylase. Bioresour Technol 123:542-547. https://doi.org/10.1016/j.biortech.2012.07.044

31. Liu J, Sun Z, Deng Y, Zou Y, Li C, Guo X, Xiong L, Gao Y, Li F, Zhao D (2009) Highly water-dispersible biocompatible magnetite particles with low cytotoxicity stabilized by citrate groups. Angew Chem Int Ed Engl 48(32):5875-5879. https://doi.org/10.1002/anie.200901566

32. Hammes GG, Wu CW (1971) Regulation of enzyme activity. The activity of enzymes can be controlled by a multiplicity of conformational equilibria. Science 172(3989):1205-1211. https://doi.org/10.1126/science.172.3989.1205

\section{Figures}
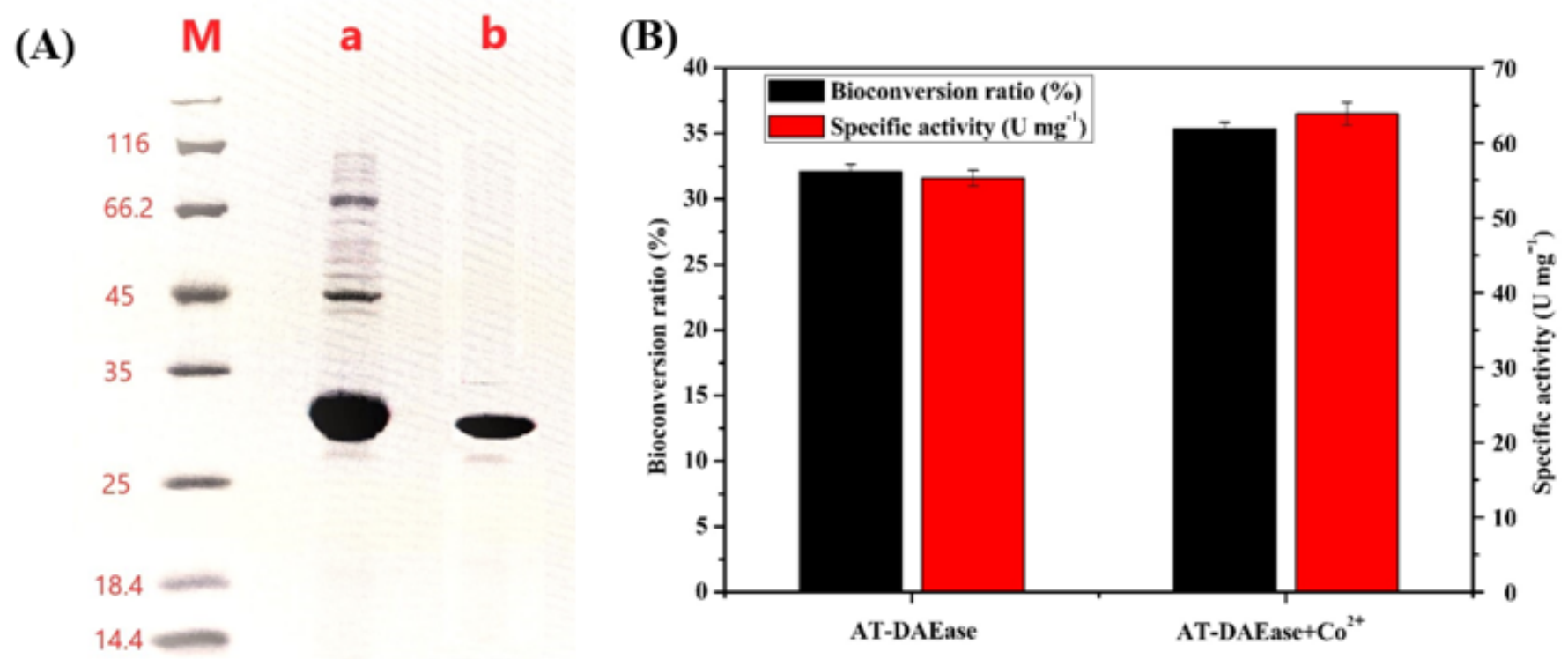

Figure 1 
Characterization of AT-DAEase. (A) SDS-PAGE of the expressed proteins. Lane M contains the molecular size markers; lane $a$ is the crude lysate of AT-DAEase, and lane $b$ is the purified $32 \mathrm{kDa}$ AT-DAEase. (B) The bioconversion ratio and specific activities of AT-DAEase in the absence and presence of $\mathrm{Co} 2+$ in the reaction system.

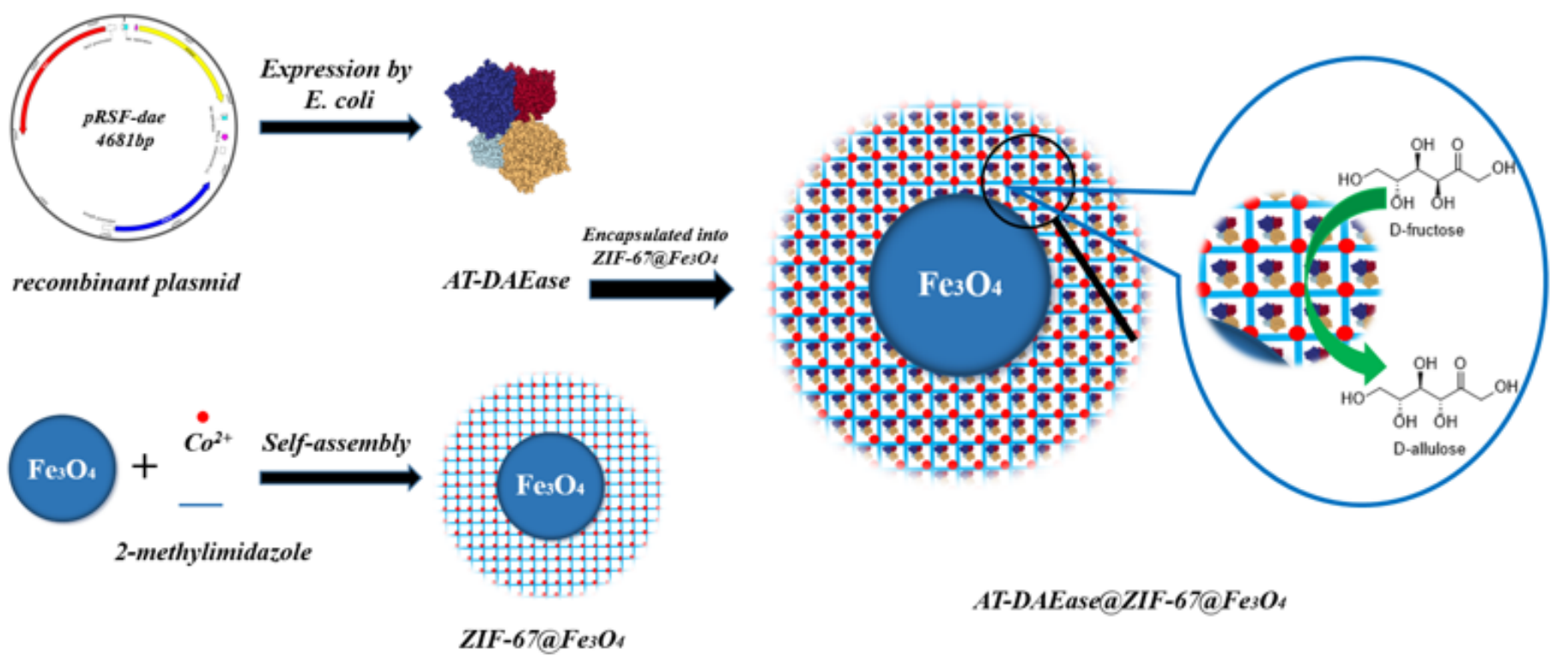

Figure 2

Immobilization of AT-DAEase into ZIF-67@Fe304. The figure presents a schematic diagram of the production of ZIF-67@Fe304 immobilized AT-DAEase. 
(A)

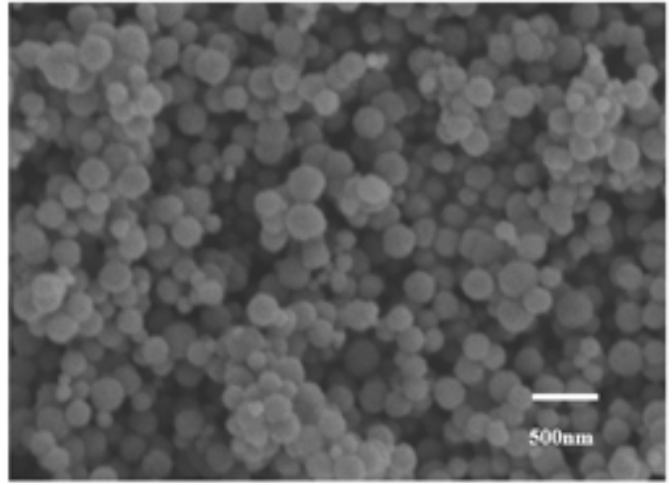

(B)

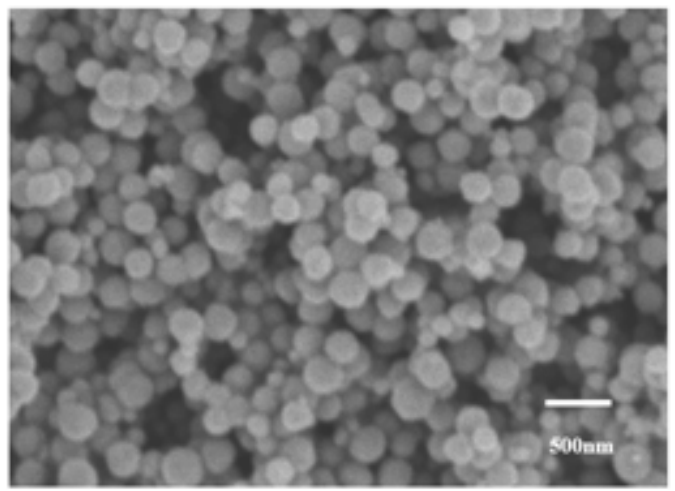

(C)

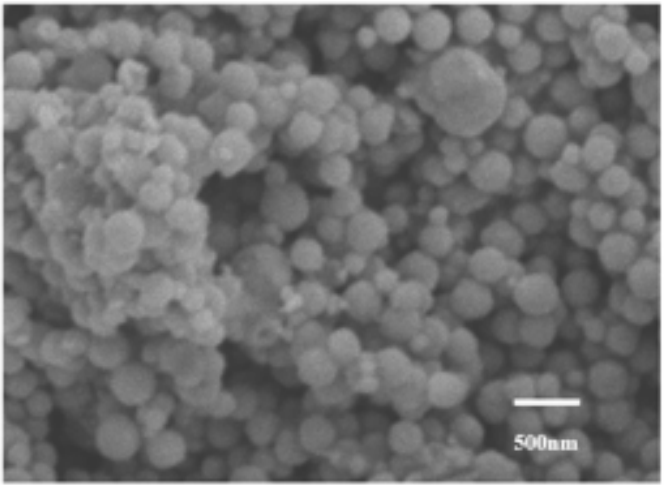

\section{Figure 3}

SEM images of (A) Fe304, (B) ZIF-67@Fe304, and (C) AT-DAEase@ZIF-67@Fe304.

(A)

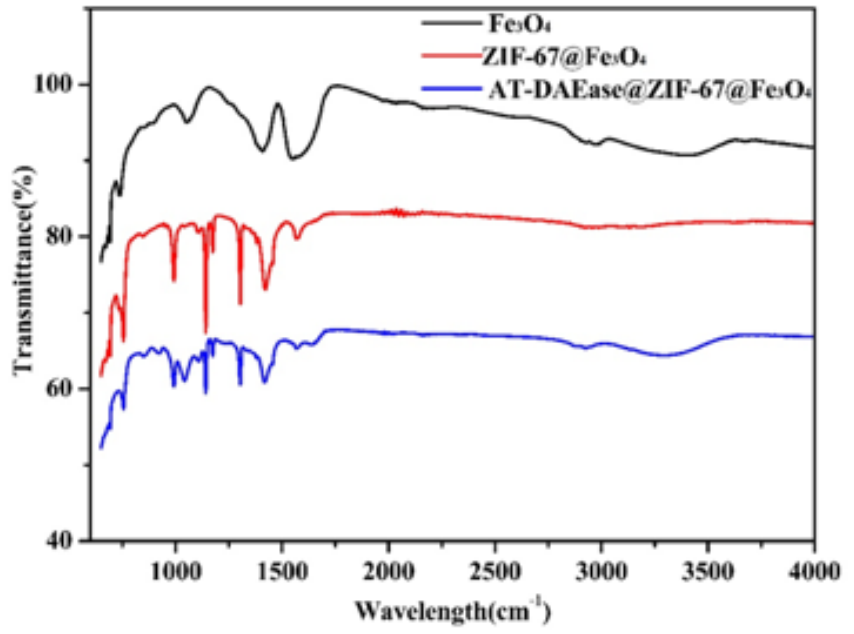

(B)

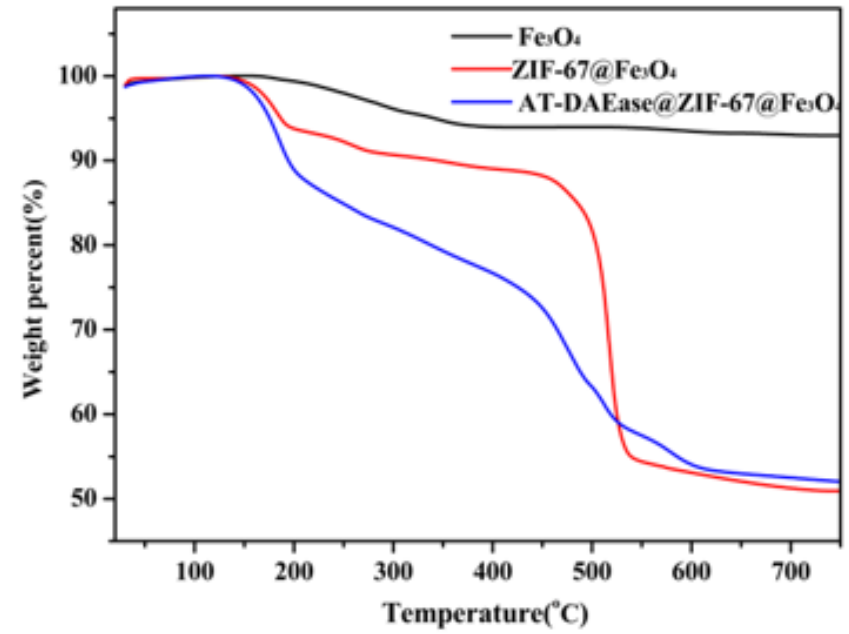

Figure 4

Fourier transforms infrared spectra (A) and thermal gravimetric analysis (B) of Fe304, ZIF-67@Fe304, and AT-DAEase@ZIF-67@Fe304. 

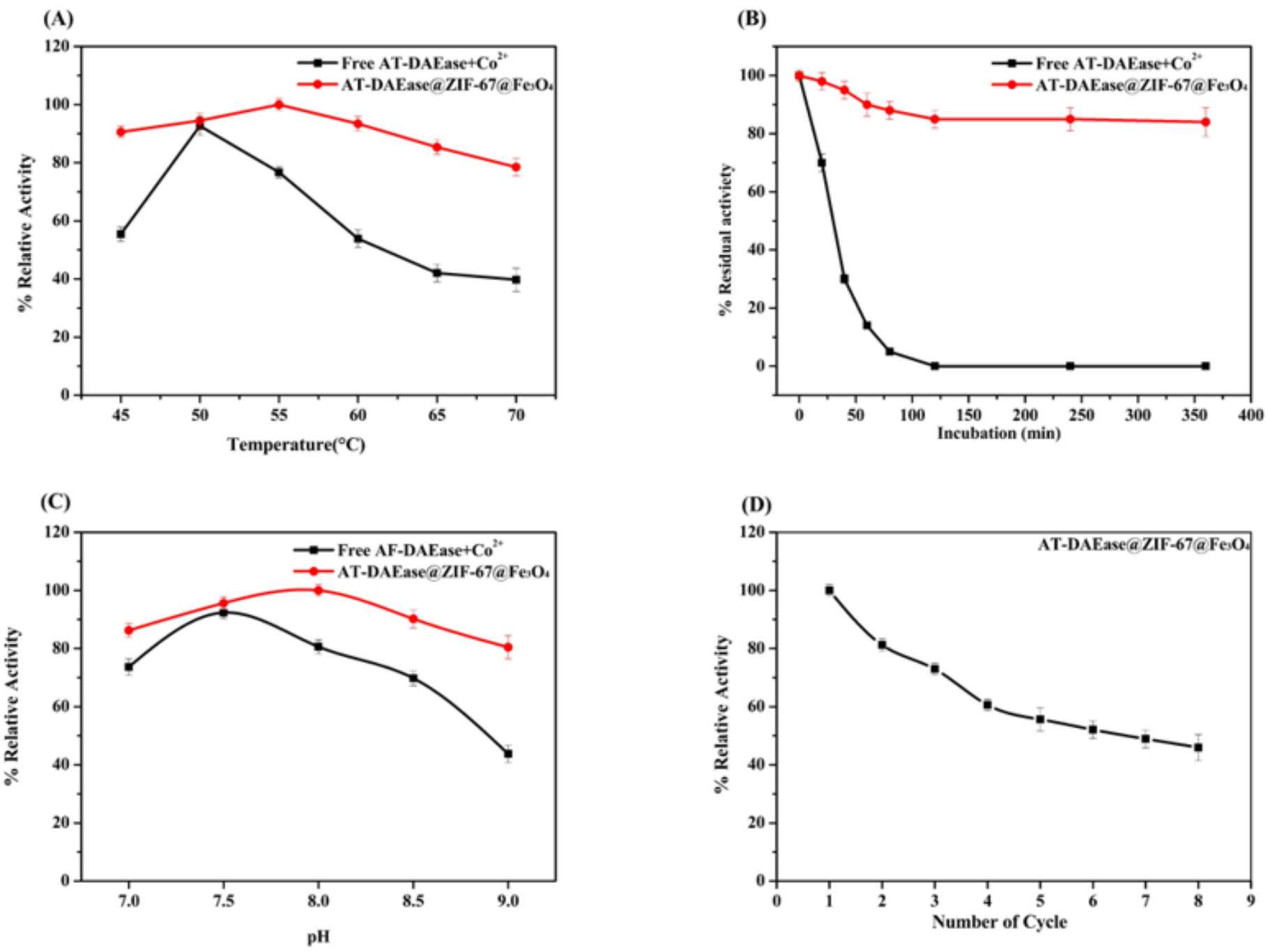

\section{Figure 5}

Reaction properties of free AT-DAEase and AT-DAEase@ZIF-67@Fe304. (A) Relative activity at different temperatures. (B) Relative activity at $55^{\circ} \mathrm{C}$ from 60 to $360 \mathrm{~min}$. (C) Relative activity at different $\mathrm{pH}$ values. (D) Relative activity of AT-DAEase@ZIF-67@Fe304 after eight cycles of use. 